\title{
Association of fission proteins with mitochondrial raft-like domains
}

\author{
L Ciarlo $^{1,4}$, V Manganelli, ${ }^{2,4}$, T Garofalo ${ }^{2}$, P Matarrese ${ }^{1}$, A Tinari ${ }^{3}$, R Misasi ${ }^{2}$, W Malorni ${ }^{*, 1,5}$ and M Sorice ${ }^{2,5}$
}

It was shown that receptor-mediated apoptosis involves a cascade of subcellular events including alterations of mitochondria. Loss of mitochondrial membrane potential that follows death receptor ligation allows the release of apoptogenic factors that result in apoptosis execution. Further important mitochondrial changes have been observed in this regard: mitochondrial remodeling and fission that appear as prerequisites for the occurrence of the cell death program. As it was observed that lipid rafts, glycosphingolipid-enriched structures, can participate in the apoptotic cascade being recruited to the mitochondria under receptor-mediated proapoptotic stimulation, we decided to analyze the possible implication of these microdomains in mitochondrial fission. We found that molecules involved in mitochondrial fission processes are associated with these domains. In particular, although hFis1 was constitutively included in mitochondrial raft-like domains, dynamin-like protein 1 was recruited to these domains on CD95/Fas triggering. Accordingly, the disruption of rafts, for example, by inhibiting ceramide synthase, leads to the impairment of fission molecule recruitment to the mitochondria, reduction of mitochondrial fission and a significant reduction of apoptosis. We hypothesize that under apoptotic stimulation the recruitment of fission-associated molecules to the mitochondrial rafts could have a role in the morphogenetic changes leading to organelle fission.

Cell Death and Differentiation (2010) 17, 1047-1058; doi:10.1038/cdd.2009.208; published online 15 January 2010

Maintenance of shape and morphology is required for normal mitochondrial and cellular functions. Mitochondria frequently undergo fission and fusion processes that regulate their morphology, number and function. ${ }^{1,2}$ This remodeling is of great relevance in both cell life and death being a mitochondrial network involved in all the main cell activities, including proliferation, differentiation and senescence, as well as cell death by apoptosis. In particular, although mitochondrial fusion processes seem to be associated with cell differentiation and senescence, ${ }^{3}$ fission processes are mandatory during cell proliferation and, as recently stated, in apoptotic events. Although mitochondrial fusion serves to maintain a tubular mitochondrial network and optimal mitochondrial function, mitochondrial fission is required in dividing cells to ensure inheritance of mitochondria by daughter cells, but it is also important during differentiation in response to new energy demands. ${ }^{4}$ Mitochondrial fission and fusion depend on the balance among several fusion and fission proteins. These include mitofusin 1 and 2 (Mfn1, Mfn2) and OPA1, which are large GTPases essential for fusion processes and localized in the mitochondria, associated with the outer (Mfn1 and 2) or inner (OPA1) membrane. ${ }^{5-7}$ On the fission side, other proteins are involved: dynamin-related protein 1, also known as dynamin-like protein 1 (DLP1), which appears to be recruited to mitochondria to mediate fission activities, ${ }^{8,9}$ and the human homologue of mitochondrial fission protein previously found in yeast, the human Fis 1 protein (hFis 1 ). It is an integral outer mitochondrial membrane protein that has an essential role in completing mitochondrial fission. ${ }^{10}$ The mitochondrial network facilitates transfer of the mitochondrial membrane potential from oxygen-rich to oxygen-poor cellular regions. Hence, unbalanced mitochondrial fission and fusion may result in breakdown of the mitochondrial network, loss of the mitochondrial DNA, respiratory defects and an increase of reactive oxygen species. ${ }^{11,12} \mathrm{~A}$ poor mitochondrial function is well recognized in aging and neurodegenerative diseases, likely having a role in their biology.

As mentioned above, mitochondrial fission has recently been reported to occur during apoptosis, induced by a variety of unrelated stimuli, ${ }^{13}$ and appears to be associated with progression of the apoptotic execution pathway. ${ }^{14}$ Two different pathways triggering apoptosis have been characterized in detail: an extrinsic pathway, involving cell-surface TNF- $\alpha$-related family of receptors and cytoplasmic adapter molecules, and an intrinsic pathway, for which mitochondrion is governed by pro- and antiapoptotic Bcl-2 family members. The intrinsic pathway is initiated by the formation of the cytosolic apoptosome, composed by Apaf-1, procaspase 9 and cytochrome $c$ released from mitochondria. ${ }^{15,16}$ Several reports indicate that mitochondria undergo rapid and

\footnotetext{
${ }^{1}$ Section of Cell Aging and Degeneration, Department of Drug Research and Evaluation, Istituto Superiore di Sanita, Rome, Italy; ${ }^{2}$ Department of Experimental Medicine, 'Sapienza' University of Rome, Rome, Italy and 'Section of Ultrastructural Infectious Pathology, Department of Technology and Health, Istituto Superiore di Sanita', Rome, Italy

*Corresponding author: W Malorni, Section of Cell Aging and Degeneration, Department of Therapeutic Research and Medicines Evaluation, Istituto Superiore di Sanita', viale Regina Elena 299, 00161 Rome, Italy. Tel: + 3906 49902905; Fax: + 3906 49903691; E-mail: malorni@iss.it

${ }^{4}$ These two authors are considered as first authors.

${ }^{5}$ These two authors are considered as senior authors.

Keywords: lipid rafts; apoptosis; mitochondria; fission

Abbreviations: Mfn1, Mfn2, mitofusin 1 and 2; DLP1, dynamin-like protein 1

Received 09.4.09; revised 23.10.09; accepted 24.11.09; Edited by L Scorrano; published online 15.1.10
} 
excessive fission evoked by several stimuli early in both extrinsic and intrinsic pathways. ${ }^{17}$ Furthermore, apoptotic mitochondrial fission appears to be independent of effector caspases. However, although there is evidence that mitochondria undergo fission in apoptosis, the molecular pathways mediating this process are still poorly understood.

Lipid rafts, defined a detergent-insoluble glycosphingolipidenriched microdomains (GEMs), have been implicated in the induction of apoptosis since many years. ${ }^{18}$ Microdomains have been shown to be essential for receptor-mediated apoptosis and they are involved in the Fas receptor contact and cell-death-inducing potency. During apoptosis, the activation of death receptors (CD95/Fas, TNF- $\alpha$ receptor) may also induce an intracellular movement of lipid raft components, for example, of GD3 ganglioside, toward mitochondria. ${ }^{19-20}$ After CD95/Fas triggering, raft-like GD3 ganglioside-enriched domains can be detected in mitochondria, where they contribute to apoptogenic events. ${ }^{19-21}$ We showed GD3 and GM3 gangliosides in isolated mitochondria from lymphoblastoid CEM cells challenged with anti-CD95/Fas and the presence of a multimolecular signaling complex on the mitochondrial outer membrane. In these raft-like domains, some molecules, including GD3, the voltage-dependent anion channel-1 and the fission protein hFis1 are enriched, whereas $\mathrm{Bcl}-2$ family proteins, including truncated Bid and Bax, are recruited. ${ }^{20}$ Other groups have also suggested that proapoptotic members of the Bcl-2 family associate with mitochondrial fission sites and mitochondrial fission proteins during apoptosis $^{22}$ and that mitochondria remodeling in terms of structural modifications, that is, their curvature changes, as well as their fission process, could be under the influence of several molecules, including lipid microdomains. ${ }^{20}$

In this paper, we analyzed the possible association of fission proteins with mitochondrial raft-like domains and showed that the mitochondrial fission molecule DLP1 can be recruited to these domains following apoptogenic stimuli, suggesting that they could correspond to the sites of fission within these organelles.

\section{Results}

\begin{abstract}
Morphological evidence of mitochondrial fission process following Fas ligation. The ultrastructural analysis of lymphoid cells undergoing apoptosis after Fas ligation clearly indicated the presence of mitochondrial fission activity in these cells (Figure 1). This was characterized by the evidence of budding regions in mitochondria ${ }^{23}$ together with small mitochondria, conceivably derived by a fission process (Figures 1b and c, compare with control untreated cells in Figure 1a). Strikingly, although thin sections $(70 \mathrm{~nm})$ such as those obtained for transmission electron microscopy (TEM) analysis by post-embedding technique can allow the maintenance of the subcellular morphology but can limit the availability of antigenic sites, IEM performed using antibody (Ab) against ganglioside GD3 clearly showed, at the mitochondrial level, the presence of gold particles specifically localized in the fission regions (Figure 1d). Gold labeling of DLP1 was as well detected in these regions (Figure 1e).
\end{abstract}

Association of mitochondria remodeling proteins with GD3. To evaluate fission proteins distribution and their possible association with mitochondrial raft-like domains, we performed immunofluorescence labeling, followed by scanning confocal microscopy analysis, either in CEM cells (not shown) or in HeLa cells (Figure 2) labeled with polyclonal $\mathrm{Ab}$ anti-hFis1 or anti-DLP1 together with antimitochondrion MoAbs (Figure 2a) or anti-GD3 MoAbs (Figure 2b).

The analysis of GD3-mitochondria association revealed that, in basal conditions, GD3 (in green) only partially colocalized with mitochondria (in red), which are organized in a well-structured network (Figure 2a, first row; note the rare overlay, i.e., the yellow areas). By contrast, after Fas triggering, colocalization areas, corresponding to the yellow fluorescence (resulting from the overlay of green and red fluorescence), were significantly more evident. In HeLa cells treated with anti-Fas, a fragmentation of the mitochondrial network can also be noted (Figure $2 \mathrm{a}$, second row). The analysis of DLP1-mitochondria association revealed very few colocalization areas in untreated cells (Figure $2 \mathrm{a}$, third row). After cell stimulation through anti-CD95/Fas, the merged image of DLP1-mitochondria revealed a massive recruitment of DLP1 to the mitochondria (Figure 2a, fourth row, yellow areas). The mitochondrial fragmentation appears evident in these micrographs.

As concerns the analysis of hFis1-GD3 association, yellow areas resulting from the overlay of green and red fluorescence were detected, which corresponded to colocalization areas (Figure $2 \mathrm{~b}$, first row). These areas were significantly more evident in anti-CD95/Fas-treated cells with respect to untreated cells, indicating that CD95/Fas triggering induces the lateral reorganization of mitochondrial raft-like microdomains where hFis1 together with GD3 was detectable (Figure 2b, second row).

The analysis of DLP1-GD3 association revealed very few colocalization areas in untreated cells (Figure $2 b$, third row). This finding suggests that DLP1 and GD3 are not associated in these cells, as expected. By contrast, after cell stimulation through anti-CD95/Fas, the merged image of anti-DLP1 and anti-GD3 staining revealed large colocalization areas (Figure 2b, fourth row). Therefore, cell triggering through anti-CD95/Fas preferentially promotes translocation of DLP1 in selective microdomains in which GD3 is highly enriched.

Distribution of mitochondria remodeling proteins in sucrose density gradient fractions. We analyzed the possible association of fission proteins in both Triton X-100insoluble and -soluble fractions after CD95/Fas triggering. As shown in Figure $3 \mathrm{a}$, the analysis of the distribution of hFis1 and OPA 1 in fractions obtained by a $5-30 \%$ linear sucrose gradient revealed that both proteins were highly enriched in fractions 4-6, corresponding to raft microdomains. This enrichment became more evident after triggering through anti-CD95/Fas as well as after staurosporine treatment (Figure 3b). As expected, in untreated cells, DLP1 (Figure 3a) was almost entirely soluble in Triton X-100. Indeed, in nonstimulated cells, DLP1 was present in fractions 6-10, but was almost completely absent in fractions 4-5, which corresponded to lipid rafts under our experimental 

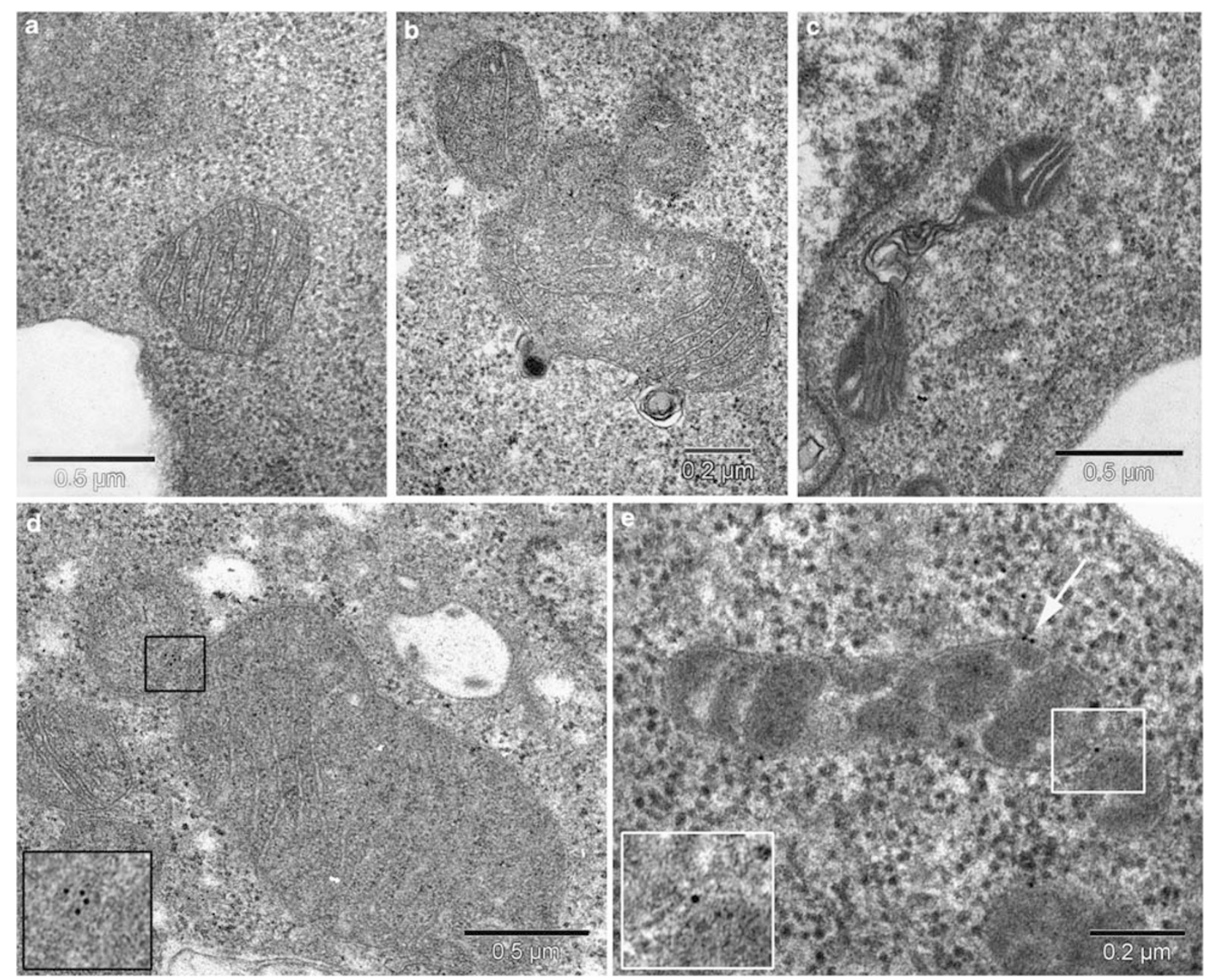

Figure 1 Morphological analyses of mitochondrial fission in CEM cells. Ultrastructural features of mitochondrial fission are observable $1 \mathrm{~h}$ after Fas ligation. Budding regions, together with small mitochondria (b) and mitochondria undergoing fission (c) were observable (compare with control cells in panel a). Immunogold labeling of ganglioside GD3 (d) and DLP-1 (e) clearly shows localization of gold particles in the putative mitochondrial fission regions. Insets show an enlarged area displaying the localization of the gold particles

conditions. After triggering through CD95/Fas, DLP1 was detected in the detergent-insoluble fractions 4-5, indicating that DLP1 was recruited to raft-like fractions on CD95/Fas ligation (Figure 3a). On the contrary, the proapoptotic protein Bak was constitutively present in mitochondrial raft-like microdomains (Figure 3a). As a control, we also analyzed the distribution of two marker proteins, one of which (CD4) is highly enriched in the raft fractions (4-6) and the other (TfR) is mainly distributed in the Triton $X-100-$ soluble fractions (9-11) (Figure 3a). These results were also quantified by densitometric analysis (Figure $3 b$ ).

Similar results were also obtained analyzing the association of mitochondria remodeling proteins in both Triton $\mathrm{X}-100$ insoluble and -soluble fractions before and after CD95/Fas triggering in HeLa cells, which represent a more suitable experimental model to study apoptosis-associated mitochondrial fission phenomenon (see Supplementary Figure 1a). Again, the enrichment of mitochondria remodeling proteins in the detergent-insoluble fractions became more evident after CD95/Fas ligation, as revealed by densitometric analysis (see Supplementary Figure 1b).

Effect of ganglioside depletion on the recruitment of
fission proteins in the Triton $\mathrm{X}-100$-insoluble fraction
obtained from isolated mitochondria. To confirm that fission proteins were present in mitochondrial raft-like microdomains, we performed the same analysis in both Triton X-100-insoluble and -soluble fractions obtained from isolated mitochondria (Figure 4). Again, we found the presence of hFis1 and OPA1 in the detergent-insoluble fraction of both untreated and anti-CD95/Fas-treated cells as well as after staurosporine treatment. On the contrary, DLP1 was almost entirely present in Triton X-100-soluble fraction of untreated cells. Conversely, after CD95/Fas triggering, as well as after staurosporine treatment, DLP1 was present in the Triton X-100-insoluble fraction. Interestingly, fumonisin B1, an inhibitor of ceramide synthase, as well as ( \pm )-threo-1-phenyl-2-decanoylamino-3-morpholino-1-propanol 
hydrochloride ([D]-PDMP), a competitive inhibitor of glucosylceramide synthetase, significantly prevented the enrichment of fission proteins in the Triton X-100-insoluble fraction.
The purity of the mitochondrial preparation was assessed by western blot by checking the endolysosomal compartment antigen Rab-5 or Golgi marker 130 (GM130). Moreover, as a
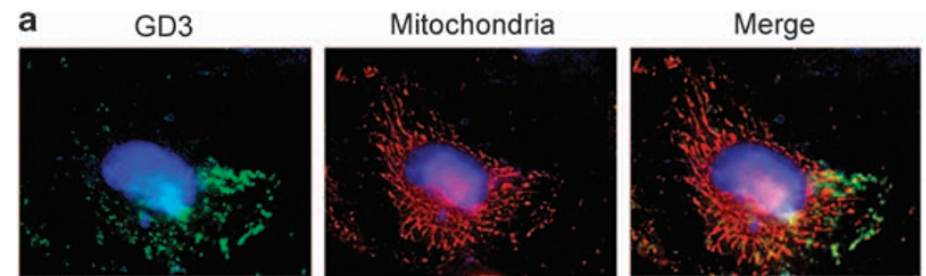

Control
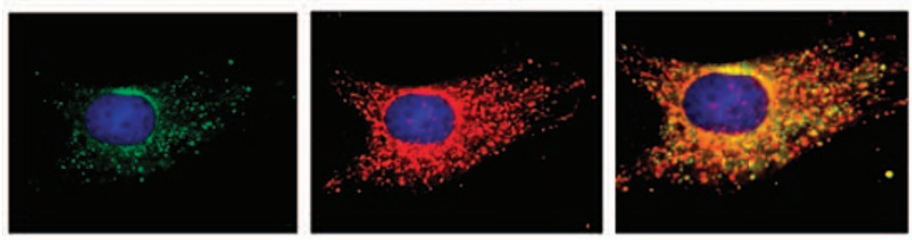

Anti-CD95

DLP1

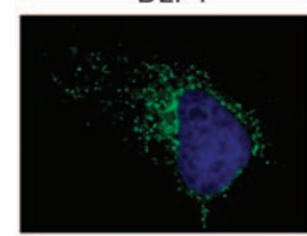

Mitochondria

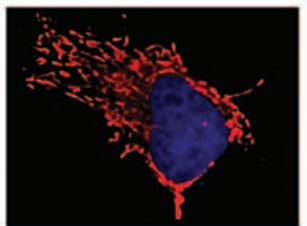

Merge

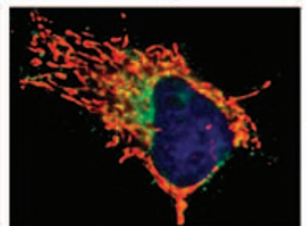

Control
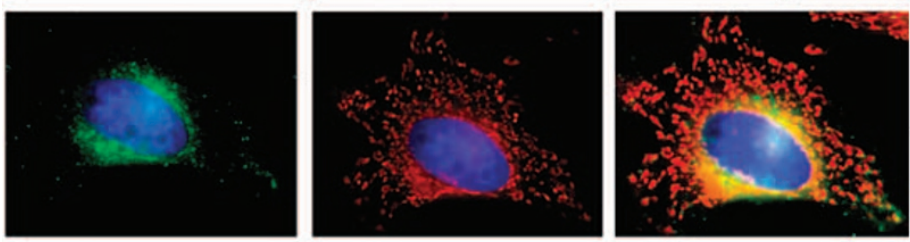

Anti-CD95

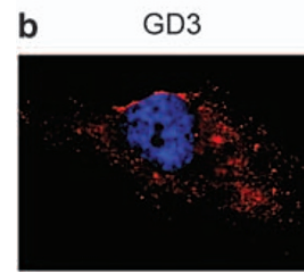

hFis1

Merge
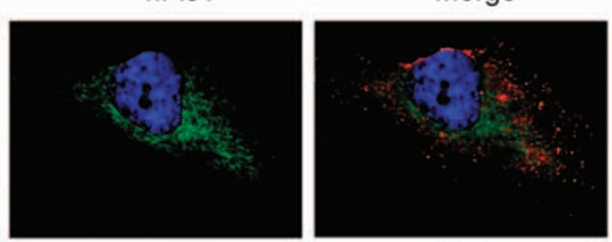

Control
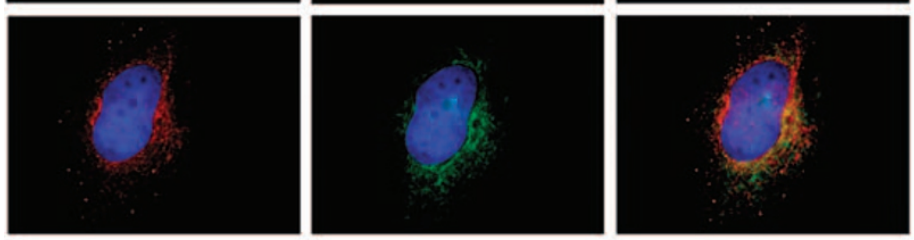

Anti-CD95

GD3

DLP1
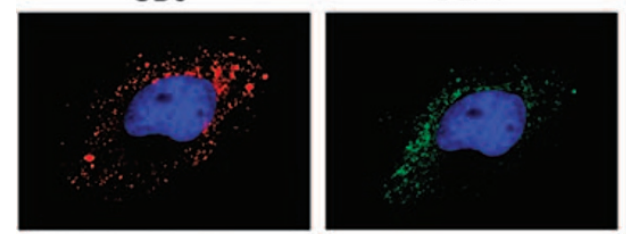

Merge

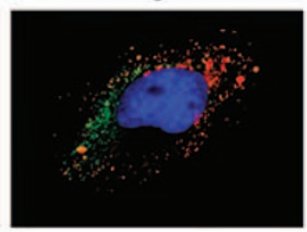

Control
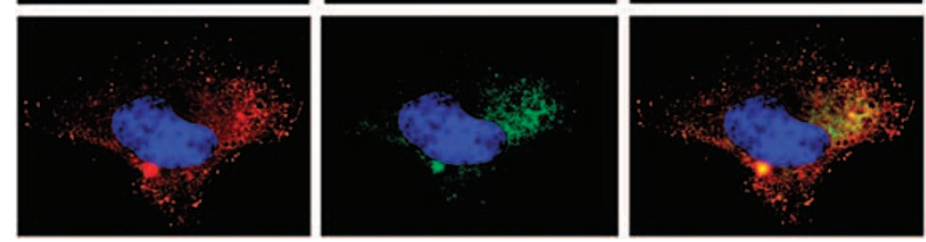

Anti-CD95 
control of the specificity of mitochondrial fraction, the presence of the mitochondrial protein ANT1 was investigated (data not shown). As a control of the raft-like fraction, GD3 was found in the Triton X-100-insoluble fraction from isolated mitochondria. After fumonisin B1 treatment, GD3 was virtually undetectable in these fractions.

Effect of fumonisin B1 treatment on ganglioside synthesis, fission proteins association and fission process. To verify whether OPA1 and DLP1 may interact with hFis1, cell lysates, obtained from CD95/Fas-treated and -untreated cells, were immunoprecipitated with anti-hFis1 $\mathrm{Ab}$, followed by protein G-acrylic beads.

The results obtained, presented in Figure $5 \mathrm{a}$, showed that in control unstimulated cells DLP1 was slightly associated with hFis1. On the contrary, after triggering with CD95/Fas, a significant proportion of DLP1 became associated with hFis1, suggesting that, after CD95/Fas stimulation, DLP1 may associate with $\mathrm{hFis} 1$ within lipid rafts. As expected, OPA1 was associated with hFis1 either in the presence or in the absence of CD95/Fas triggering. No bands were detected after CD95/Fas stimulation in control immunoprecipitation experiments with an IgG having irrelevant specificity. The immunoprecipitation was verified by western blot (Figure 5a).

To analyze the effect of ganglioside depletion on the association of fission proteins with $\mathrm{hFis} 1$, we performed the same experiments in cells pretreated with fumonisin B1, an inhibitor of ceramide synthase (Figure 5b). The results showed that pretreatment with this compound completely prevented OPA1 and DLP1 association with hFis1, further showing a role for ganglioside in fission proteins association. As a control, we observed that pretreatment with fumonisin B1 resulted in quite complete disappearance of the ganglioside GD3 (Figure 5c). To go deep inside the effects of ganglioside depletion on the mitochondrial fission process, we analyzed, by flow cytometry, physical parameters of mitochondria isolated from untreated and fumonisin B1-treated cells, and from CD95/Fas-treated cells, in the presence or absence of pretreatment with fumonisin B1 (Figure 6a). We observed that $1 \mathrm{~h}$ treatment with anti-CD95/Fas induced a significant reduction of the forward scatter, indicating a reduction in mitochondrial size (middle dot plot, boxed area) with respect to untreated cells (left dot plot, boxed area). This size reduction could indicate that a mitochondrial fission process was occurring. Importantly, and according to the biochemical data described above, pretreatment with fumonisin B1 (right dot plot, boxed area) prevented CD95/Fasinduced reduction of mitochondrial dimension. Administration of fumonisin alone did not modify the physical parameters of mitochondria (not shown). The confocal microscopy observations after cell staining with MitoTracker-Green (Figure $6 \mathrm{~b}$ and
Supplementary Figure 2) seem to confirm this hypothesis. In fact, the fragmentation of mitochondria, a typical fissionassociated feature, was observed in CEM cells treated with anti-CD95/Fas for $1 \mathrm{~h}$ (Figure 6b, central picture) or $3 \mathrm{~h}$ (not shown), but not in the cells treated with fumonisin B1 before CD95/Fas administration (right picture), which appeared very similar to untreated control cells (left picture). Morphometric analyses also highlight a time-dependent effect of anti-CD95/ Fas in inducing mitochondrial fission (Figure 6c). As expected, and according to data from the literature ${ }^{24}$ fumonisin B1 pretreatment also resulted in a significant reduction (more than $50 \%$ ) of the anti-CD95/Fas-induced apoptosis (Figure 6d). Fluorescence microscopy observations performed on HeLa cells stained with anti-mitochondria (Figure 6e) confirmed data obtained on CEM cells. In fact, fragmentation of the mitochondrial network was observed after Fas triggering (central picture, compare with untreated cells in left picture) but not in cells treated with fumonisin B1 before anti-Fas administration (right picture).

Effect of hFis1 silencing on DLP1 recruitment on mitochondrial lipid rafts. Moreover, to better verify the specificity of DLP1 recruitment through mitochondrial lipid rafts, we performed western blot analysis of mitochondrial Triton X-100-soluble and -insoluble fractions obtained from hFis siRNA-transfected cells after apoptosis triggering. In our experimental conditions, we found that $72 \mathrm{~h}$ after siRNA addition (hFis1 siRNA or nonsilencing-siRNA) (i) more than $95 \%$ of HeLa cells were transfected (Supplementary Figure $3 a$ ) and (ii) in cells transfected with hFis1 siRNA, a significant reduction (more than $80 \%$ ) of hFis1 expression, with respect to nonsilencing siRNA-transfected HeLa cells, was detectable. These results were also confirmed by western blot analysis (Supplementary Figure 3b, left panel) followed by densitometric analysis (Supplementary Figure $3 b$, right panel). The results of these experiments showed that the recruitment of DLP1 to mitochondrial raft-like microdomains was partially prevented in hFis siRNAtransfected cells (Figure 7a). These results were also confirmed by confocal microscopy observations. In fact, in scrambled control cells, triggering through anti-CD95/Fas leads to the recruitment of DLP1 to mitochondria (Figure 7b, see yellow areas in the merge picture, first row). This antiFas-induced relocalization of DLP1 was prevented, at least in part, in hFis1 knocked down HeLa cells (see merge picture, second row). Importantly, as expected, the dramatic fragmentation of the mitochondrial network, induced by anti-Fas treatment in scrambled control cells (third row, left panel), was completely hindered in hFis1-silenced cells (third row, right panel).

\footnotetext{
Figure 2 Evidence for the existence of fission protein-enriched raft-like microdomains in mitochondria. Immunofluorescence analysis of HeLa cells, either untreated or treated with anti-CD95/Fas $\left(250 \mathrm{ng} / \mathrm{ml} \mathrm{ON}\right.$ at $\left.37^{\circ} \mathrm{C}\right)$. (a) After mitochondrial staining (red fluorescence), HeLa cells were labeled with anti-GD3 (green fluorescence; first and second row, untreated and Fas-treated cells, respectively) and anti-DLP1 (green fluorescence, third and fourth row, untreated and Fas treated cells, respectively). To note the yellow fluorescence (resulting from the overlap of green and red fluorescence) indicating the relocalization of GD3 and DLP1 at the mitochondrial level after Fas triggering. (b) After GD3 staining (red fluorescence), HeLa cells were labeled with anti-hFis1 (green fluorescence, first and second rows, untreated and Fas-treated cells, respectively) and anti-DLP1 (green fluorescence, third and fourth rows, untreated and Fas-treated cells, respectively). The yellow fluorescence areas observed in the merged picture indicate the colocalization of GD3 with hFis1 or DLP1 in cells treated with anti-Fas. Magnification: $\times 1000$
} 


\section{Discussion}

This work is focused at the comprehension of the possible implication of lipid microdomains in the process of mitochondrial fission, thought to hinge on a series of protein molecules constitutively expressed on mitochondria or recruited to the organelle under proapoptotic stimulation. We show that these GEMs could participate in mitochondrial remodeling and fission, at least under receptor-triggered apoptosis. We found
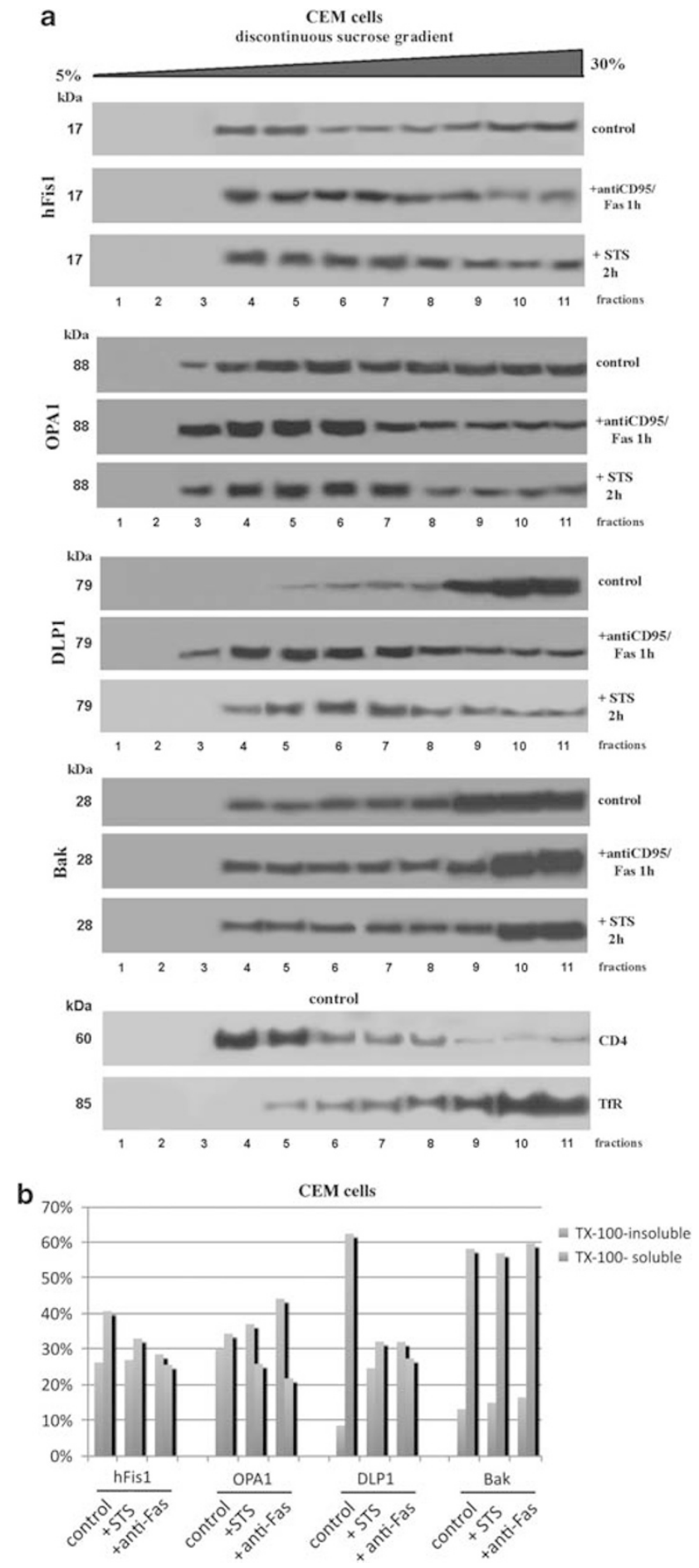

that mitochondrial raft-like domains can be detected in cells after CD95/Fas ligation, according to Garofalo et al..$^{20}$ and, more importantly, we also found that molecules involved in mitochondrial fission processes are associated with these domains. In particular, although hFis1 appears to be constitutively included in mitochondrial raft-like domains, DLP1 is recruited to raft-like microdomains only on CD95/ Fas triggering. Interestingly, the disruption of rafts, for example, by cyclodextrin, by fumonisin B1 (an inhibitor of ceramide synthase also proposed for pharmacological use ${ }^{24}$ ) as well as by [D]-PDMP (an inhibitor of glucosyltransferase), leads to an impairment of fission molecule recruitment to the mitochondria, a reduction of mitochondrial fission and a significant reduction of apoptosis. Altogether, these findings clearly suggest that receptor-mediated apoptosis, which is known to depend on a key downstream role of mitochondrial alterations, needs lipid raft integrity and function to proceed.

As previously suggested by us and by other authors, lipid rafts could act as a sort of signaling device and/or by a 'chamber' catalyzing key critical reactions as those determining cell fate. ${ }^{25-27}$ In fact, the function of rafts as catalytic sites at the plasma membrane was hypothesized since many years. ${ }^{18}$ They are necessary for CD95/Fas death signaling, that is, for receptor efficiency and death domain assembly. However, the role of lipid rafts in death execution seems to be not merely limited to the plasma membrane, as a role for microdomains has also been observed in the propagation of death stimuli. After the pioneering studies by the group of De Maria ${ }^{21,22}$ suggesting an intracellular trafficking of glycosphingolipids, we have shown that (i) the cytoplasmic trafficking of ganglioside GD3, considered as a paradigmatic component of glycosphingolipid microdomains, could occur through its association with cytoskeletal components ${ }^{28}$ and (ii) mitochondrial fission-associated proteins are recruited to 'raft-like' lipid microdomains under proapoptotic stimulation. ${ }^{20}$ Hence, the data presented here seem to add a novel role for these lipid microdomains, which could contribute to mitochondria remodeling that precedes apoptosis execution.

Figure 3 Lipid microdomain localization of mitochondria remodeling proteins in CEM cells. (a) Western blot analysis of sucrose gradient fractions. CEM cells, either untreated or treated with anti-CD95/Fas $\left(250 \mathrm{ng} / \mathrm{ml}\right.$ for $1 \mathrm{~h}$ at $\left.37^{\circ} \mathrm{C}\right)$, and staurosporine, $1 \mu \mathrm{M}$ for $2 \mathrm{~h}$ at $37^{\circ} \mathrm{C}$, were lysed and the supernatant fraction was subject to sucrose density gradient. After centrifugation, the gradient was fractioned and each gradient fraction was recovered and analyzed by western blot analysis. First line: fractions obtained after sucrose density gradient, either untreated or treated with anti-CD95/Fas, and treated with STS, were analyzed using an antihFis1 polyclonal Ab. Second line: fractions obtained after sucrose density gradient, either untreated or treated with anti-CD95/Fas, and treated with STS, were analyzed using an anti-OPA1 MoAb. Third line: fractions obtained after sucrose density gradient, either untreated or treated with anti-CD95/Fas, and treated with STS, were analyzed using an anti-DLP1 MoAb. Fourth line: fractions obtained after sucrose density gradient, either untreated or treated with anti-CD95/Fas, and treated with STS, were analyzed using an anti-Bak polyclonal Ab. Fifth line: as a control, fractions obtained after sucrose density gradient from untreated cells were analyzed using an anti-CD4 MoAb or an anti-TfR MoAb. The fraction samples were loaded by volume. (b) Densitometric analysis of sucrose gradient fractions. The columns indicate the percent distribution across the gel of fractions 3-4 and 5 (raft-fractions) and $9-10$ and 11 (Triton X-100-soluble fractions), as detected by densitometric scanning analysis 


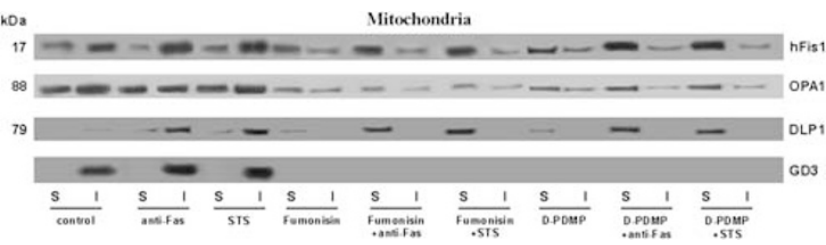

Figure 4 Association of mitochondria remodeling proteins with Triton X-100insoluble fractions obtained from isolated mitochondria. Isolated mitochondria from CEM cells, either untreated or treated with anti-CD95/Fas $(250 \mathrm{ng} / \mathrm{ml}$ for $1 \mathrm{~h}$ at $37^{\circ} \mathrm{C}$ ), staurosporine $1 \mu \mathrm{M}$ for $2 \mathrm{~h}$ at $37^{\circ} \mathrm{C}$, with or without preincubation with fumonisin B1 or [D]-PDMP, were detergent solubilized as reported in Materials and Methods. Both Triton X-100-soluble (S) and -insoluble (I) fractions were analyzed by western blot analysis and probed with anti-hFis1 polyclonal Ab, anti-OPA1 MoAb and anti-DLP1 MoAb. The fraction samples were loaded by volume. Alternatively, isolated mitochondria treated as above were subjected to ganglioside extraction. The extracts were run on HPTLC aluminum-backed silica gel and analyzed for the presence of GD3, using an anti-GD3 MoAb (GMR19)

The process of mitochondrial fission has been recently analyzed in a number of works that essentially claim for (i) proteins that seem to have a role in the mitochondrial fusion (e.g., mitofusins), often associated with cell aging and (ii) proteins that are involved in the fission process (e.g., dynein GTPase DLP1, hFis), associated either with cell proliferation, when daughter cells need their own energy factories, or with cell death by apoptosis, when fission process precedes the release of apoptogenic factors by mitochondria. For instance, it is well known that on apoptotic stimulation DLP1 is recruited to the mitochondrial outer membrane, where it colocalizes with Bax and Mfn2 at the fission sites. ${ }^{29,30}$ For example, DLP1 function is required for apoptotic mitochondrial fission and cytochrome $c$ release. $^{31}$ In addition, it has also been suggested that OPA1, a profusion dynamin-related protein involved in cristae remodeling, could represent a further actor participating in mitochondrial changes during apoptosis. ${ }^{32-35}$ However, the submitochondrial localization of this protein appears still controversial. Indeed, a differential localization of different OPA1 isoforms has been observed. It has been suggested that the $88 \mathrm{kDa}$ isoform preferentially associates with the outer membrane. ${ }^{36}$ In our experiments, we found that this isoform is present in raft-like microdomains and coimmunoprecipitates with hFis 1 on apoptotic stimulation. At present, we cannot rule out the possibility that further unidentified molecules could participate in the interaction between OPA1 and hFis1 proteins. Finally, as mitochondria fission includes a profound mitochondrial remodeling and changes of mitochondrial membrane curvature, it was suggested that changes of lipid and glycolipid moieties could at least participate, if not have a critical role, in the morphogenetic changes of mitochondria in cells undergoing apoptosis. On the basis of our experimental results, we can include lipid rafts in the complex molecular framework leading to mitochondrial fission: their presence can provide catalytic domains where unknown molecular associations and/or cleavages could occur, whereas their impairment also impairs fission and apoptosis. The role of the ganglioside in this multimolecular system could be to facilitate the transient and local formation of inverted hexagonal structures in mitochondrial membrane that undergo the fission process, for example, modifying mitochondrial membrane curvature and fluidity.
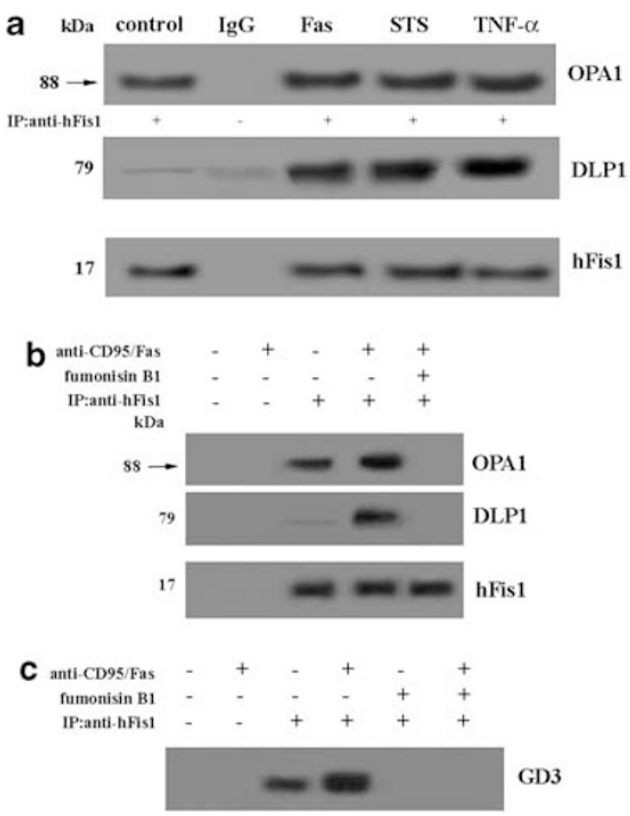

Figure 5 (a) Association of fission protein after different apoptotic signals. CEM cells, either untreated or treated with anti-CD95/Fas $\left(250 \mathrm{ng} / \mathrm{ml}\right.$ for $1 \mathrm{~h}$ at $\left.37^{\circ} \mathrm{C}\right)$, with $1 \mu \mathrm{M}$ staurosporine for $2 \mathrm{~h}$ at $37^{\circ} \mathrm{C}$ or with TNF- $\alpha, 1 \mathrm{ng} / \mathrm{ml}$, for $2 \mathrm{~h}$ at $37^{\circ} \mathrm{C}$, were lysed in lysis buffer, followed by immunoprecipitation with rabbit anti-hFis1. A rabbit IgG isotypic control was used. The immunoprecipitates were subjected to $7.5 \%$ SDS-PAGE. Membranes were probed with anti-OPA1 MoAb and with anti-DLP1 MoAb. As a control, immunoprecipitates were assessed by immunoblot with anti$\mathrm{hFis} 1 \mathrm{MoAb}$. (b) Effect of fumonisin B1 on lipid microdomain localization of fission protein. CEM cells, either untreated or treated with anti-CD95/Fas $(250 \mathrm{ng} / \mathrm{ml}$ for $1 \mathrm{~h}$ at $37^{\circ} \mathrm{C}$ ) and with or without preincubation with fumonisin $\mathrm{B} 1$, were lysed in lysis buffer, followed by immunoprecipitation with rabbit anti-hFis1. A rabbit IgG isotypic control was used. The immunoprecipitates were subjected to 7.5\% (SDS-PAGE). Membranes were probed with anti-OPA1 MoAb and with anti-DLP1 MoAb. As a control, immunoprecipitates were assessed by immunoblot with anti-hFis1 MoAb. (c) Effect of fumonisin B1 on GD3 expression. Alternatively, the immunoprecipitates were subjected to ganglioside extraction. The extracts were run on HPTLC aluminum-backed silica gel and analyzed for the presence of GD3, using an antiGD3 MoAb (GMR19)

Mitochondrial lipid microdomains may thus represent essential activating platforms where specific key reactions can take place and be catalyzed, contributing to mitochondriamediated events leading to cell survival or death.

\section{Materials and Methods}

Cells and treatments. Human lymphoblastoid CEM cells and HeLa cells were maintained in RPMI 1640 medium or DMEM (both Gibco-BRL, Life Technologies Italia, Milano, Italy), respectively, containing $10 \%$ fetal calf serum (FCS) and $100 \mathrm{U} / \mathrm{ml}$ penicillin and $100 \mathrm{mg} / \mathrm{ml}$ streptomycin, at $37^{\circ} \mathrm{C}$ in a humidified $5 \% \mathrm{CO}_{2}$ atmosphere.

Apoptosis was induced by incubating cells at a concentration of $5 \times 10^{5} \mathrm{per} \mathrm{ml}$ in serum-free medium supplemented with insulin $(5 \mu \mathrm{g} / /)$ and transferrin $(5 \mu \mathrm{g} / \mathrm{l})$, and by adding anti-Fas (CD95) IgM MoAb (clone CH11; Upstate Biotechnology, Lake Placid, NY, USA) at $250 \mathrm{ng} / \mathrm{ml}$ for different incubation times; indeed, to induce apoptosis, CEM cells were treated with $1 \mu \mathrm{M}$ staurosporine (Sigma, St. Louis, MO, USA) for $2 \mathrm{~h}$ at $37^{\circ} \mathrm{C}$ or with TNF- $\alpha, 1 \mathrm{ng} / \mathrm{ml}$, for $2 \mathrm{~h}$ at $37^{\circ} \mathrm{C}$ (PeproTech, Rochy Hill, $\mathrm{NJ}$, USA). To analyze the effect of sphingolipid depletion, cells were treated with $30 \mu \mathrm{M}$ fumonisin B1 (FB1; Sigma) (inhibitor of ceramide synthase) for $24 \mathrm{~h}$ at $37^{\circ} \mathrm{C}^{37}$ or with $30 \mu \mathrm{M}$ [D]-PDMP (Sigma), a competitive inhibitor of glucosylceramide synthetase, for 5 days at $37^{\circ} \mathrm{C} .{ }^{38}$ After treatments, cells were collected and prepared for other procedures, as described below. 
Knock down hFis1 by siRNA. HeLa cells were seeded $\left(2 \times 10^{4}\right.$ cells per dish) in a $60 \mathrm{~mm}$ dish in DMEM containing serum and antibiotics. Twenty-four hours after seeding, HeLa cells were transfected with GeneSolution siRNA (Qiagen
Sciences, Germantown, MD, USA), according to the manufacturer's instructions, using $5 \mathrm{nM}$ Smart pool siRNA hFis1. As experimental control, cells were also transfected with $5 \mathrm{nM}$ of nonsilencing siRNA (AllStars Negative Control). The a

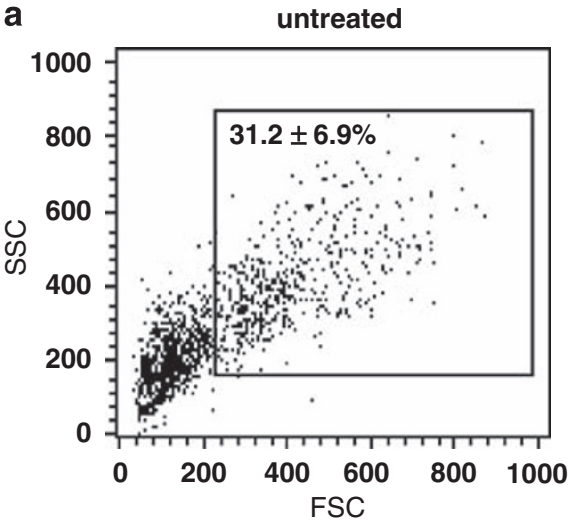

b

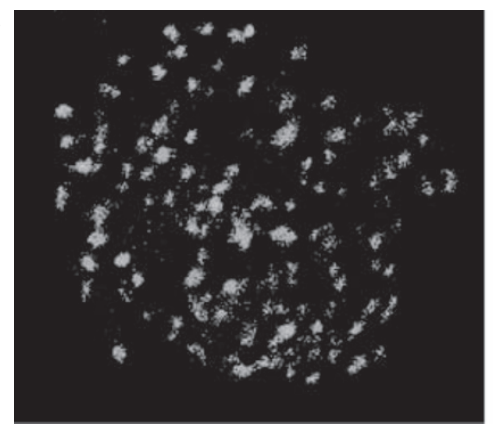

C

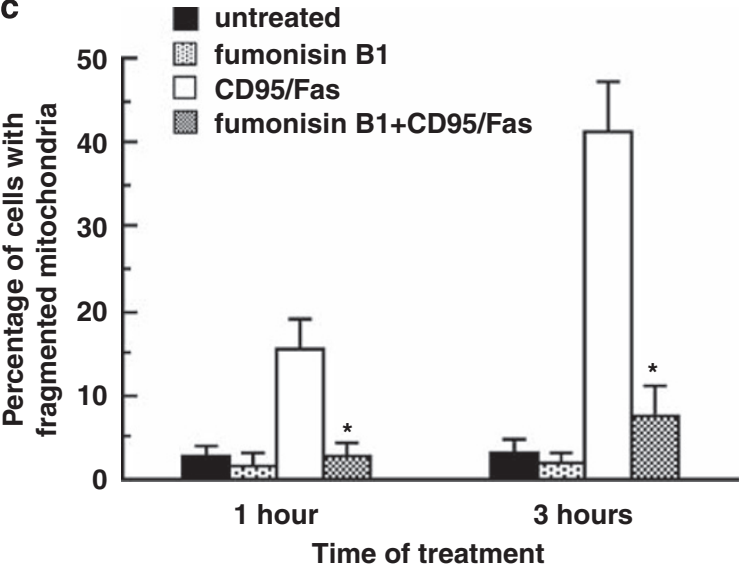

Anti-Fas1h

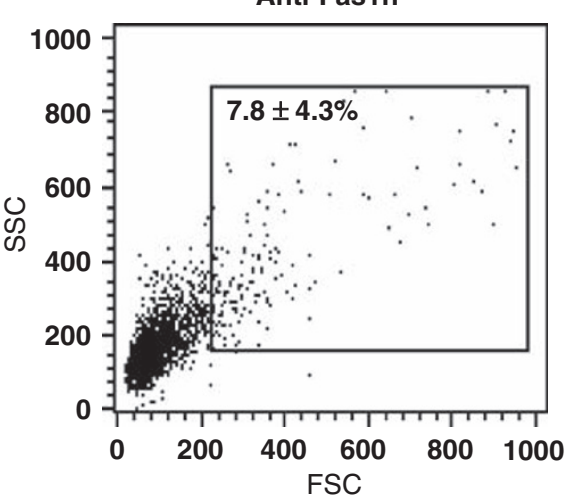

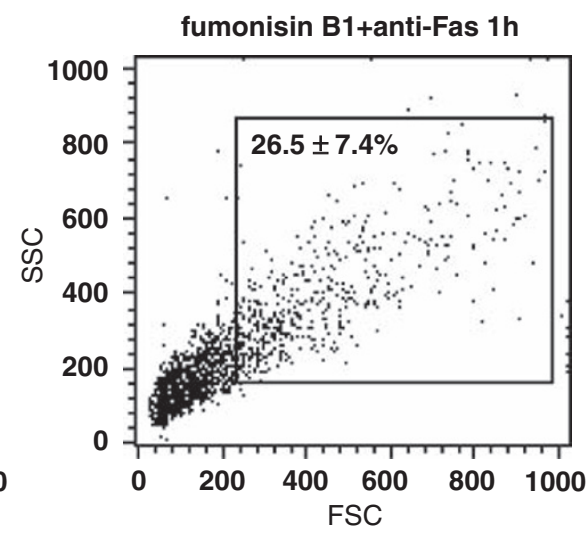
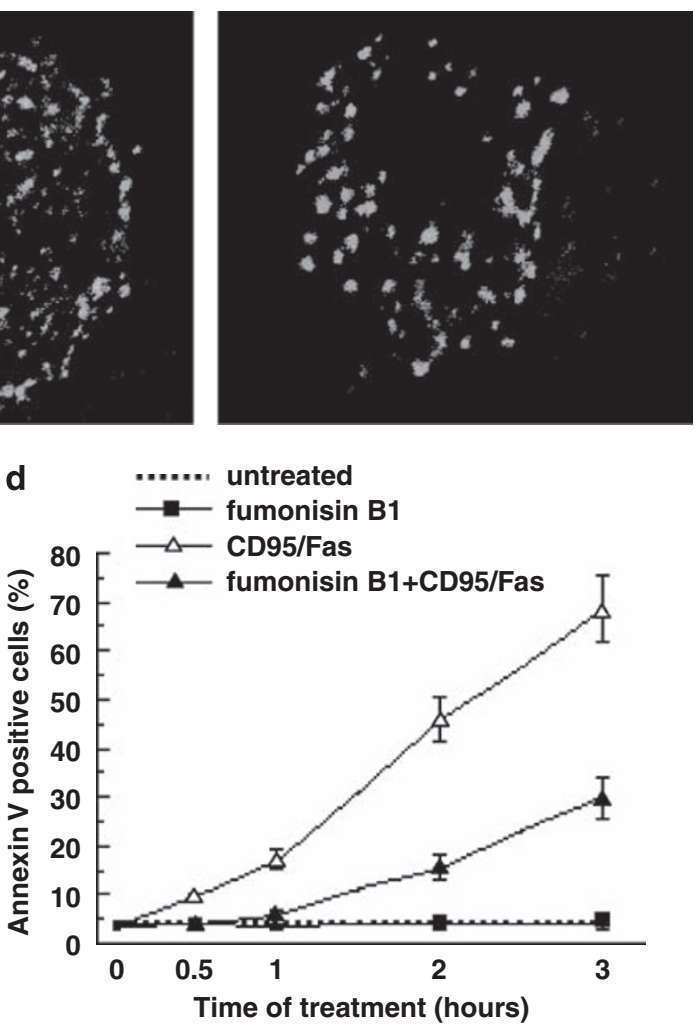

e untreated

Anti-Fas ON

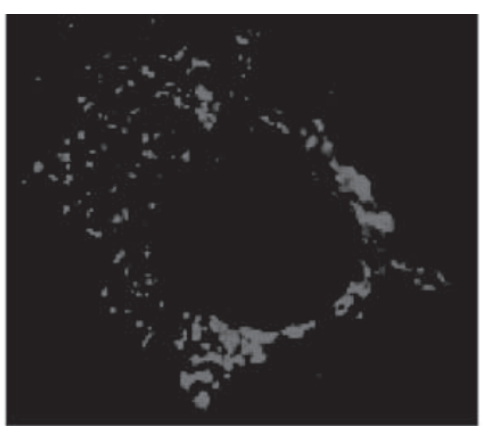

fumonisin B1+anti-Fas ON

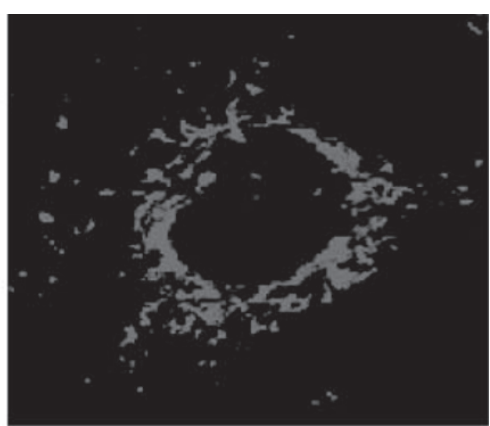


transfection efficiency was evaluated by flow cytometry in cells transfected with Qiagen's positive silencing siRNA (FITC-siRNA). After $72 \mathrm{~h}$, the effect of transfection was verified by either flow cytometry or western blot analyses by using hFis1 polyclonal Ab. After transfection, cells were treated with anti-CD95/Fas overnight and then prepared for biochemical and morphological analyses.

\section{Electron microscopy}

Transmission electron microscopy. For TEM examination, cells were fixed in $2.5 \%$ cacodylate-buffered $(0.2 \mathrm{M}, \mathrm{pH} 7.2)$ glutaraldehyde for $20 \mathrm{~min}$ at room temperature and postfixed in $1 \% \mathrm{OsO}_{4}$ in cacodylate buffer for $1 \mathrm{~h}$ at room temperature. Fixed specimens were dehydrated through a graded series of ethanol solutions and embedded in Agar 100 (Agar Aids, Cambridge, UK). Serial ultrathin sections were collected on 200-mesh grids and then counterstained with uranyl acetate and lead citrate. Sections were observed with a Philips 208 electron microscope at $80 \mathrm{kV}$ (Philips Company, Eindhoven, The Netherlands). Immunoelectron microscopy. Thin sections, collected on gold grids, were treated with PBS containing $1 \%(\mathrm{w} / \mathrm{v})$ gelatin, $1 \% \mathrm{BSA}, 5 \% \mathrm{FCS}$ and $0.05 \%$ Tween 20 and then incubated with mAbs raised against GD3 ganglioside (GMR19; Seikagaku, Chuo-ku, Tokyo, Japan) or anti DLP1 MoAb (BD Biosciences Pharmingen, San Jose, CA, USA), diluted 1:10 in the same buffer without gelatin overnight at $4^{\circ} \mathrm{C}$. After washing for $1 \mathrm{~h}$ at room temperature, sections were labeled with protein A-10 nm gold conjugate $(1: 10)$ for $1 \mathrm{~h}$ at room temperature and washed again. Negative controls were incubated with the gold-conjugated alone.

Immunofluorescence analysis and confocal microscopy. Control and treated cells were fixed with $4 \%$ paraformaldehyde and then permeabilized by $0.5 \%(\mathrm{v} / \mathrm{v})$ Triton $\mathrm{X}-100$. After washings, cells were incubated with MoAb to mitochondria (Chemicon, Temecula, CA, USA) for $1 \mathrm{~h}$ at $4^{\circ} \mathrm{C}$. After washings, cells were incubated with AlexaFluor 594-conjugated anti-mouse IgG for an additional $30 \mathrm{~min}$. After washings, cells were incubated for $1 \mathrm{~h}$ at $4^{\circ} \mathrm{C}$ with anti-GD3 MoAb (Seikagaku), followed by AlexaFluor 488-conjugated anti-mouse IgM (Molecular Probes) or with anti-hFis1 polyclonal Ab (Alexis Biochemicals, San Diego, CA, USA) or anti-polyclonal Ab DLP1 (Santa Cruz Biotechnology, Santa Cruz, CA, USA), followed by AlexaFluor 488-conjugated anti-rabbit (Molecular Probes). All samples were counterstained with Hoechst 33342, mounted with glycerol-PBS $(2: 1)$ and analyzed by using an Olympus fluorescence microscope (Olympus Corporation, Tokyo, Japan) or an inverted confocal microscope (Nikon Ti-E, NIKON Corporation, Tokyo, Japan) (see below).

Cells were stained with MitoTracker-Green ( $1 \mu \mathrm{M}$; Molecular Probes) for $45 \mathrm{~min}$ at $37^{\circ} \mathrm{C}$. After this time, cells were washed in PBS three times and then fixed with $4 \%$ paraformaldehyde in PBS for $30 \mathrm{~min}$ at room temperature. HeLa cells knocked down for $\mathrm{hFis} 1$ protein, untreated and treated with anti-CD95/Fas overnight, were fixed with $4 \%$ paraformaldehyde in PBS for $30 \mathrm{~min}$ at room temperature and then permeabilized with $0.5 \%$ Triton X-100 in PBS for $5 \mathrm{~min}$ at room temperature, as previously reported. ${ }^{20,39}$ After three washes in PBS, samples were incubated with (i) anti-mitochondrion MoAb (Chemicon) followed by AlexaFluor 488-conjugated or AlexaFluor 594-conjugated anti-mouse IgG and (ii) anti-DLP1 polyclonal antibody (Santa Cruz Biotechnology) for $1 \mathrm{~h}$ at $4^{\circ} \mathrm{C}$, followed by AlexaFluor 488-conjugated or Cy5-conjugated anti-goat IgG (Molecular Probes). After washings in PBS, cells were counterstained with Hoechst dye (Molecular Probes) and, finally, resuspended in $0.1 \mathrm{M}$ Tris- $\mathrm{HCl}(\mathrm{pH} 9.2)$ containing $60 \%$ glycerol $(\mathrm{v} / \mathrm{v})$ and observed by using an inverted microscope (Nikon Ti-E) equipped with a confocal spectral imaging system (Nikon D Eclipse C1si) using a (Nikon) planapo objective $\times 60$ oil A.N. 1.4.
Excitation light was obtained by a Laser Dapi $408 \mathrm{~nm}$ from Hoechst, an Argon lon Laser $(488 \mathrm{~nm})$ from Alexa 488 and MitoTracker-Green, Diode Laser HeNe $(561 \mathrm{~nm})$ from Alexa 594 and a Red Diode Laser $(638 \mathrm{~nm})$ from Cy5. Emitted fluorescence was recorded in spectral-frame lambda mode. Hoechst emission was recorded from 415 to $485 \mathrm{~nm}$. Alexa 488 and MitoTracker-Green emissions from 495 to $550 \mathrm{~nm}$. Alexa 594 emission from 583 to $628 \mathrm{~nm}$ and Cy5 from 634 to $750 \mathrm{~nm}$. Images recorded have an optical thickness of $0.20 \mu \mathrm{m}$ and have been analyzed by the C1-LCSI EZ-C1 software for spectral analysis.

Morphometric analyses. The evaluation of the percentage of cells with mitochondria undergoing fission was performed by confocal microscopy analysis in CEM cells stained with MitoTracker-Green or in HeLa cells after double labeling with anti-DLP1 polyclonal $\mathrm{Ab}$ and anti-mitochondrial MoAb. Fluorescence images were analyzed counting at least 200 cells for each experimental point. Only those cells in which DLP1-mitochondrial overlapping was observed were considered undergoing mitochondrial fission.

Isolation and analysis of GEM fraction. GEM fraction from lymphoblastoid CEM cells and from HeLa cells, either untreated or treated with anti-CD95/Fas, was isolated as previously described. ${ }^{40}$ The optimal incubation time with anti-CD95/Fas $\left(1 \mathrm{~h}\right.$ at $\left.37^{\circ} \mathrm{C}\right)$ was selected on the basis of preliminary experiments. Briefly, $2 \times 10^{8}$ cells were suspended in $1 \mathrm{ml}$ of lysis buffer, containing $1 \%$ Triton X-100, $10 \mathrm{mM}$ Tris- $\mathrm{HCl}(\mathrm{pH} 7.5), 150 \mathrm{mM} \mathrm{NaCl}, 5 \mathrm{mM}$ EDTA, $1 \mathrm{mM}$ $\mathrm{NaVO}_{4}$ and $75 \mathrm{U}$ of aprotinin and allowed to stand for $20 \mathrm{~min}$. The cell suspension was mechanically disrupted by Dounce homogenization (10 strokes). The lysate was centrifuged for $5 \mathrm{~min}$ at $1300 \times g$ to remove nuclei and large cellular debris. The supernatant fraction (postnuclear fraction) was subjected to sucrose density gradient centrifugation; that is, the fraction was mixed with an equal volume of $85 \%$ sucrose (w/v) in lysis buffer ( $10 \mathrm{mM}$ Tris- $\mathrm{HCl}(\mathrm{pH} 7.5), 150 \mathrm{mM} \mathrm{NaCl}, 5 \mathrm{mM}$ EDTA). The resulting diluent was placed at the bottom of a linear sucrose gradient $(5-30 \%)$ in the same buffer and centrifuged at $200000 \times g$ for $16-18 \mathrm{~h}$ at $4^{\circ} \mathrm{C}$ in an SW41 rotor (Beckman Institute, Palo Alto, CA, USA). After centrifugation, the gradient was fractionated, and 11 fractions were collected starting from the top of the tube. All steps were carried out at $0-4^{\circ} \mathrm{C}$. The fraction samples were loaded by volume.

Alternatively, mitochondria isolated from cells, either untreated or treated with anti-CD95/Fas, were detergent solubilized according to Skibbens et al. ${ }^{41}$ Briefly, mitochondria were lysed with $1 \mathrm{ml}$ of extraction buffer ( $25 \mathrm{mM} \mathrm{HEPES}(\mathrm{pH} 7.5), 0.15$ $\mathrm{NaCl}, 1 \%$ Triton X-100 and 100 kallikrein $\mathrm{U} / \mathrm{ml}$ aprotinin) for $20 \mathrm{~min}$ on ice. Lysates were collected and centrifuged for 2 min in a Brinkmann microfuge at 12000 r.p.m. at $4^{\circ} \mathrm{C}$. Supernatants containing Triton $\mathrm{X}-100$ soluble material were collected; pellets were undertaken to a second centrifugation $(30 \mathrm{~s})$ to remove the remaining soluble material. The pellets were then solubilized in $100 \mathrm{ml}$ buffer containing $50 \mathrm{mM}$ Tris- $\mathrm{HCl}$ ( $\mathrm{pH} 8.8), 5 \mathrm{mM}$ EDTA and $1 \%$ SDS. DNA was sheared by passage through a 22-gauge needle. Both Triton X-100-soluble and -insoluble material were analyzed by western blot analysis, as previously reported. ${ }^{39}$ The fraction samples were loaded by volume.

Immunoblotting analysis of GEM fraction. All the fractions obtained as reported above were subjected to SDS-polyacrylamide gel electrophoresis (SDS-PAGE). The proteins were electrophoretically transferred onto polyvinylidene difluoride membranes (Biorad Laboratory GmbH, Munchen, Germany). Membranes were blocked with $5 \%$ defatted dried milk in TBS, containing $0.05 \%$ Tween 20 and probed with anti-hFis1 polyclonal Ab (Alexis Biochemicals), anti-OPA1 MoAb (BD

\footnotetext{
Figure 6 Effect of fumonisin B1 treatment on anti-CD95/Fas-induced fission process. (a) Flow cytometry analysis of physical parameters of mitochondria isolated from untreated cells (left panel), anti-CD/95-treated cells (central panel) and cells pretreated with fumonisin B1 before anti-CD95/Fas administration (right panel). The reduction of the forward scatter observed in a CD95/Fas-treated sample, indicating a reduction in mitochondrial size, was counteracted by fumonisin B1 pretreatment. Numbers in the boxed areas indicate the percentage of mitochondria with high forward scatter. (b) Confocal microscopy micrographs after cell staining with MitoTracker-Green show that mitochondrial fission, detectable in anti-CD95/Fas-treated cells (central panel), was prevented in cells pretreated with fumonisin B1 (right panel), which appeared very similar to untreated control cells (left panel). (c) Morphometric analysis of the mitochondria fission process indicated a time-dependent effect of anti-CD95/Fas in inducing mitochondrial fission. In ordinates, the percentage of cells with fragmented mitochondria is shown. Data are reported as mean \pm S.D. of the results obtained in three independent experiments. Asterisk (*) indicates $P<0.01$ versus anti-CD95/Fas-treated cells by Student's $t$-test. (d) Quantification of CD95/Fas-induced apoptosis after cell staining with annexin V-FITC indicated a significant decrease in the apoptotic rate in cells pretreated with fumonisin B1 before anti-CD95/Fas administration in comparison with anti-CD95/Fas-treated cells. Data are reported as mean \pm S.D. of the results obtained in four independent experiments. (e) Immunofluorescence analysis of HeLa cells after staining with anti-mitochondria antibodies. To note the fragmentation of mitochondrial network in Fas-triggered cells (central panel) that was prevented by fumonisin pretreatment (left panel; compare with control untreated cells in right panel)
} 


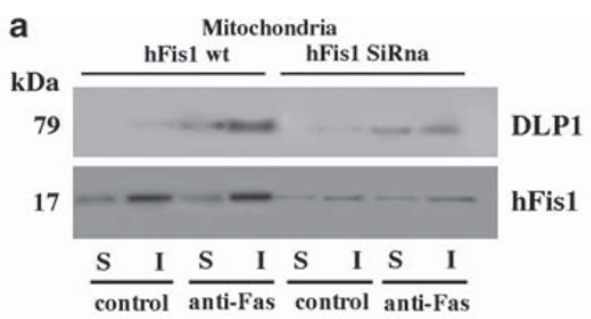

b

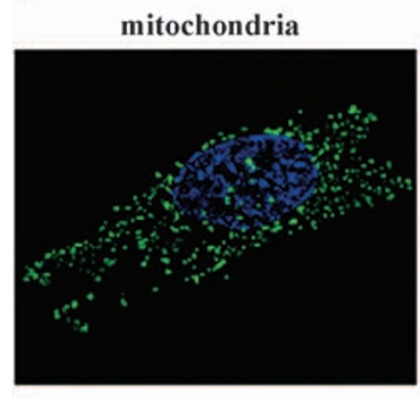

mitochondria

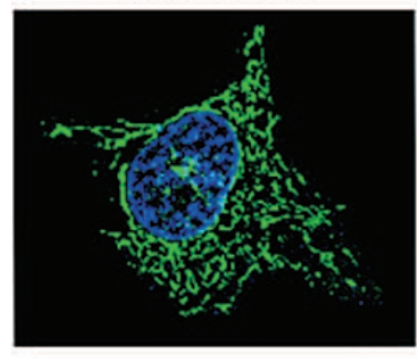

Scrambled control + anti-Fas

$$
\text { DLP1 }
$$

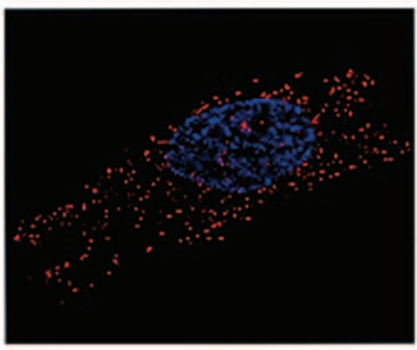

hFis1 siRNA + anti-Fas

DLP1

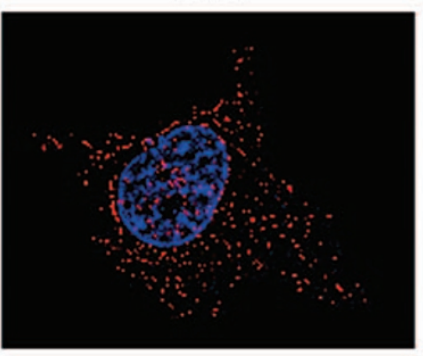

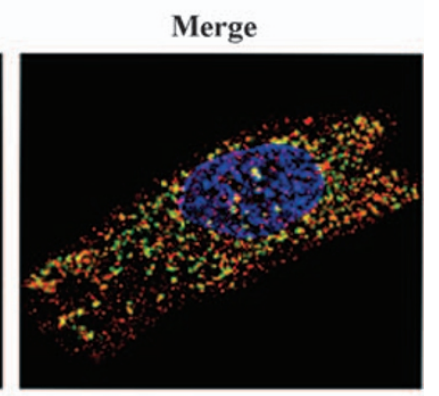

Merge

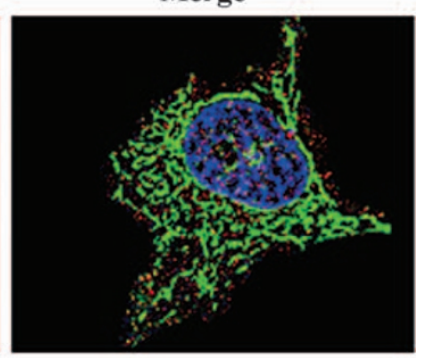

Mitochondrial network 3D reconstruction

Scrambled control + anti-Fas

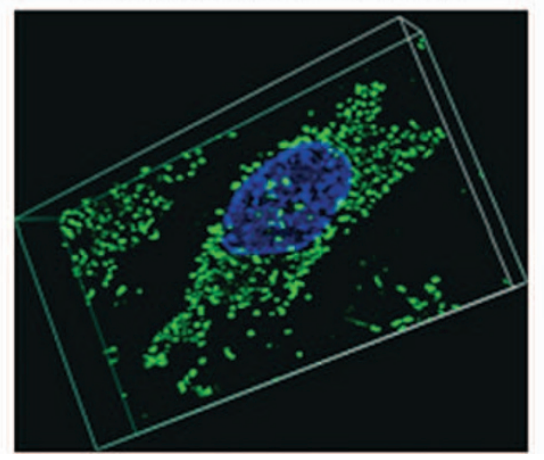

\begin{abstract}
hFis1 siRNA + anti-Fas
\end{abstract}

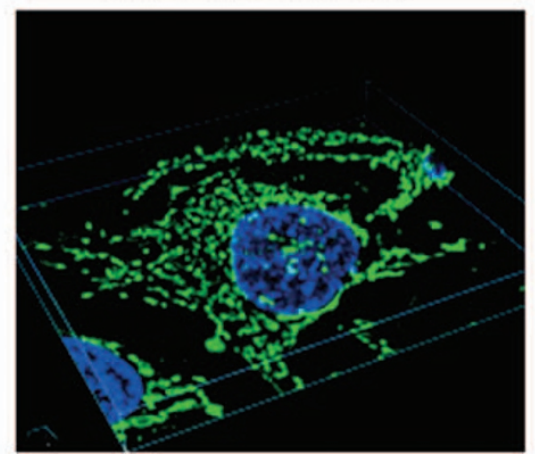

Figure 7 Effect of hFis1 knocking down by siRNA on anti-CD95/Fas-induced fission process in HeLa cells. (a) DLP1 distribution in mitochondrial Triton X-100-soluble and -insoluble fractions following hFis1 silencing. Isolated mitochondria from control (nonsilencing siRNA) or hFis1-depleted (hFis1 siRNA) HeLa cells, either untreated or treated with anti-CD95/Fas (overnight at $37^{\circ} \mathrm{C}$ ), were detergent solubilized as reported in Materials and Methods. Both Triton X-100 'S' and 'l' fractions were analyzed by western blot analysis and probed with anti-DLP1 MoAb or with anti-hFis1 polyclonal Ab. (b) Confocal microscopy analysis. Confocal microscopy micrographs of HeLa cells. After mitochondrial staining (green fluorescence), cells were labeled with anti-DLP1 (red fluorescence). To note the yellow fluorescence (resulting from the overlap of green and red fluorescence) indicating the relocalization of DLP1 at the mitochondrial level after Fas triggering in scrambled control cells (first row) but not in hFis1-silencing cells (second row). 3D reconstruction of mitochondrial network (third row) shows anti-Fas-induced mitochondria fragmentation in scrambled control cells (left panel) but not in hFis1silencing cells (right panel). Magnification: $\times 1000$

Biosciences Pharmingen), anti-DLP1 MoAb (BD Biosciences Pharmingen), antiBak polyclonal Ab (Santa Cruz Biotechnology), anti-TfR MoAb (Abcam, Cambridge, UK) or anti-CD4 MoAb (Santa Cruz Biotechnology). Bound antibodies were visualized with HRP-conjugated anti-rabbit IgG or anti-mouse IgG (Sigma) and immunoreactivity assessed by chemiluminescence reaction, using the ECL Western blocking detection system (Amersham Biosciences, Buckinghamshire, UK). Densitometric scanning analysis was performed by Mac OS 9.0 (Apple Computer International, Cupertino, CA, USA) using NIH Image 1.62 software. The density of each band in the same gel was analyzed, values were totaled and then the percent distribution across the gel was detected. 
Analysis of hFis1 immunoprecipitates. CEM cells, untreated or treated with anti-CD95/Fas $\left(250 \mathrm{ng} / \mathrm{ml}\right.$ for $1 \mathrm{~h}$ at $\left.37^{\circ} \mathrm{C}\right)$, were lysed in lysis buffer $(10 \mathrm{nM}$ Tris-HCL (pH 8.0), $150 \mathrm{mM} \mathrm{NaCl}, 1 \%$ Nonidet P-40, $1 \mathrm{mM}$ phenylmethylsulfonyl fluoride (PMSF), $10 \mathrm{mg} / \mathrm{ml}$ leupeptin). Cell-free lysates were mixed with protein G-acrylic beads and stirred by a rotary shaker for $2 \mathrm{~h}$ at $4^{\circ} \mathrm{C}$ to preclear nonspecific binding. After centrifugation $(500 \times g$ for $1 \mathrm{~min})$, the supernatant was immunoprecipitated with anti-hFis1 polyclonal Ab (Alexis Biochemicals), plus protein G-acrylic beads.

A rabbit IgG isotypic control (Sigma) was used. The immunoprecipitates were split into two aliquots. The first one was checked by western blot analysis, using antiDLP1 MoAb (BD Biosciences Pharmingen) or anti-OPA1 MoAb (BD Biosciences Pharmingen).

The second one was subjected to ganglioside extraction, according to the method of Svennerholm and Fredman ${ }^{42}$ as reported below.

Ganglioside analysis in the immunoprecipitates of the hFis1. Briefly, samples were extracted twice in chloroform/methanol/water $(4: 8: 3)(\mathrm{v} / \mathrm{v} / \mathrm{v})$ and subjected to Folch partition by the addition of water resulting in a final chloroform/methanol/water ratio of $1: 2: 1.4$. The upper phase, containing polar glycosphingolipids, was purified of salts and low molecular weight contaminants using Bond elut C18 columns (Superchrom, Milan, Italy), according to the method of Williams and McCluer. ${ }^{43}$ The eluted glycosphingolipids were dried down and separated by HPTLC, using aluminum-backed silica gel $60(20 \times 20)$ plates (Merck, Darmstadt, Germany). Chromatography was performed in chloroform/methanol/ aqueous $\mathrm{KCl}(0.25 \%) \quad(5: 4: 1) \quad(\mathrm{v} / \mathrm{v} / \mathrm{v})$. The dried chromatograms were soaked for $90 \mathrm{~s}$ in a $0.5 \%(\mathrm{w} / \mathrm{v})$ solution of poly(iso)bytyl methacrylate) beads (Polysciences, Wirrington, PA, USA) dissolved in hexane. The plates were immunostained for $1 \mathrm{~h}$ at room temperature with GMR19 anti-GD3 MoAb (Seikagaku) and then with HRP-conjugated anti-mouse IgM (Sigma). Immunoreactivity was assessed by chemiluminescence reaction, using the $\mathrm{ECL}$ Western detection system (Amersham Biosciences).

Preparation of isolated mitochondria. Control and treated cells were resuspended in Homo buffer (10 mM HEPES (pH 7.4), $1 \mathrm{mM}$ ethylene glycol-bis (-aminoethyl ether) $N, N^{\prime}, N^{\prime \prime}$-tetraacetic acid, $0.1 \mathrm{M}$ sucrose, $5 \% \mathrm{BSA}, 1 \mathrm{mM}$ PMSF and complete protease inhibitor cocktail (Roche, Indianapolis, IN, USA) for $10 \mathrm{~min}$ on ice. Cells were homogenized with a Teflon homogenizer with B-type pestle ${ }^{44}$ for $10 \mathrm{~min}$ at $4^{\circ} \mathrm{C}$ to remove intact cells and nuclei. The supernatants were further centrifuged at $10000 \times g$ at $4^{\circ} \mathrm{C}$ for $10 \mathrm{~min}$ to precipitate the heavy membrane fractions (enriched in mitochondria). These fractions were then purified by standard differential centrifugation. The purity of our mitochondrial preparation was then tested by staining with MoAb specific to the endolysosomal compartment or Golgi vesicle antigens, Rab-5 and GM130, respectively (both from Santa Cruz Biotechnology). Results showed that the isolated mitochondria were almost completely negative either for the endolysosomal compartment antigen Rab-5 or for GM130, a protein that characterizes Golgi apparatus, whereas they were strongly positive for the mitochondrial protein ANT1 (data not shown).

\section{Conflict of interest}

The authors declare no conflict of interest.

Acknowledgements. We are indebted to Dr. Mario Falchi and Dr. Lucrezia Gambardella for their invaluable assistance in confocal microscopy and analytical cytology analyses. This work was partially supported by PRIN-MIUR to MS and by Telethon (GGP06254B) and FIRB-MIUR (RBPR05NWWC_011) to WM and ItaliaUSA (530F/0F21) to PM.

1. Karbowski M, Youle RJ. Dynamics of mitochondrial morphology in healthy cells and during apoptosis. Cell Death Diff 2003; 10: 870-880.

2. Cerveny KL, Tamura $Y$, Zhang Z, Jensen RE, Sesaki $H$. Regulation of mitochondrial fusion and division. Trends Cell Biol 2007; 17: 563-569.

3. Nicholls DG. Mitochondrial function and dysfunction in the cell: its relevance to aging and aging-related disease. Int J Biochem Cell Biol 2002; 34: 1372-1381.

4. Green DR, Kroemer G. The pathophysiology of mitochondrial cell death. Science 2004; 305: 626-629.

5. Olichon A, Emorine LJ, Descoins E, Pelloquin L, Brichese L, Gas N et al. The human dynamin-related protein OPA1 is anchored to the mitochondrial inner membrane facing the inter-membrane space. FEBS Lett 2002; 523: 171-176.
6. Chen H, Detmer SA, Ewald AJ, Grifn EE, Fraser SE, Chan DC. Mitofusins Mfn1 and Mfn2 coordinately regulate mitochondrial fusion and are essential for embryonic development. J Cell Biol 2003; 160: 189-200.

7. Cipolat S, Martins de Brito O, Dal Zilio B, Scorrano L. OPA1 requires mitofusin 1 to promote mitochondrial fusion. Proc Natl Acad Sci USA 2004; 101: 15927-15932.

8. Yoon Y, Pitts KR, Dahan S, McNiven MA. A novel dynamin-like protein associates with cytoplasmic vesicles and tubules of the endoplasmic reticulum in mammalian cells. $J$ Cell Biol 1998; 140: 779-793.

9. Pitts KR, Yoon Y, Krueger EW, McNiven MA. The dynamin-like protein DLP1 is essential for normal distribution and morphology of the endoplasmic reticulum and mitochondria in mammalian cells. Mol Biol Cell 1999; 10: 4403-4417.

10. Yoon $\mathrm{Y}$, Krueger EW, Oswald BJ, McNiven MA. The mitochondrial protein $\mathrm{hFis} 1$ regulates mitochondrial fission in mammalian cells through an interaction with the dynamin-like protein DLP1. Mol Cell Biol 2003; 23: 5409-5420.

11. Zamzami N, Marchetti P, Castedo M, Zanin C, Vayssiere JL, Petit PX et al. Reduction in mitochondrial potential constitutes an early irreversible step of programmed lymphocyte death in vivo. J Exp Med 1995; 181: 1661-1672.

12. Parone PA, Da Cruz S, Tondera D, Mattenberger $\mathrm{Y}$, James DI, Maechler $\mathrm{P}$ et al. Preventing mitochondrial fission impairs mitochondrial function and leads to loss of mitochondrial DNA. PLOS ONE 2008; 3: e3257.

13. Frank S, Gaume B, Bergmann-Leitner ES, Leitner WW, Robert EG, Catez F et al. The role of dynamin-related protein-1, a mediator of mitochondrial fission, in apoptosis. Dev Cell 2001; 1: 515-525.

14. Bossy-Wetzel E, Barsoum MJ, Godzik A, Schwarzenbacher R, Lipton SA. Mitochondrial fission in apoptosis, neurodegeneration and aging. Curr Opin Cell Biol 2003; 15: 706-716.

15. Ferri KF, Kroemer GK. Organelle-specific initiation of cell death pathways. Nat Cell Biol 2001; 3: 255-263.

16. Green DR, Evan GI. A matter of life and death. Cancer Cell 2002; 1: 19-30.

17. Scorrano L, Ashiya M, Buttle K, Weiler S, Oakes SA, Mannella CA et al. A distinct pathway remodels mitochondrial cristae and mobilizes cytochrome $c$ during apoptosis. Dev Cell 2002; 2: 55-67.

18. Garofalo T, Misasi R, Mattei V, Giammarioli AM, Malorni W, Pontieri GM et al. Association of the death-inducing signaling complex with microdomains after triggering through CD95/ Fas. Evidence for caspase-8-ganglioside interaction in T cells. J Biol Chem 2003; 278: $8309-8315$.

19. Garcia-Ruiz C, Colell A, Morales A, Calva M, Enrich C, Fernandez-Checa JC. Trafcking of ganglioside GD3 to mitochondria by tumor necrosis factor-alpha. J Biol Chem 2002; 277 : 36443-36448.

20. Garofalo T, Giammarioli AM, Misasi R, Tinari A, Manganelli V, Gambardella L et al. Lipid microdomains contribute to apoptosis-associated modifications of mitochondria in T cells. Cell Death Differ 2005; 12: 1378-1389.

21. De Maria R, Lenti L, Malisan F, d'Agostino F, Tomassini B, Zeuner A et al. Requirement for GD3 ganglioside in CD95- and ceramide-induced apoptosis. Science 1997; 277: 1652-1655.

22. Brooks $C$, Wei $Q$, Feng $L$, Dong G, Tao $Y$, Mei $L$ et al. Bak regulates mitochondrial morphology and pathology during apoptosis by interacting with mitofusins. Proc Natl Acad Sci USA 2007; 104: 11649-11654.

23. Matarrese P, Tinari A, Mormone E, Bianco GA, Toscano MA, Ascione B et al. Galectin-1 sensitizes resting human $T$ lymphocytes to Fas (CD95)-mediated cell death via mitochondrial hyperpolarization, budding, and fission. J Biol Chem 2005; 280: $6969-6985$

24. Cuzzocrea S, Di Paola R, Genovese T, Mazzon E, Esposito E, Crisafulli C et al. Antiinflammatory and anti-apoptotic effects of fumonisin $B 1$, an inhibitor of ceramide synthase, in a rodent model of splanchnic ischemia and reperfusion injury. J Pharmacol Exp Ther 2008; 327: 45-57.

25. Malorni W, Giammarioli AM, Garofalo T, Sorice M. Dynamics of lipid raft components during lymphocyte apoptosis: the paradigmatic role of GD3. Apoptosis 2007; 12: 941-949.

26. Garofalo T, Tinari A, Matarrese P, Giammarioli AM, Manganelli V, Ciarlo $L$ et al. Do mitochondria act as 'cargo boats' in the journey of GD3 to the nucleus during apoptosis? FEBS Lett 2007; 581: 3899-3903.

27. Scorrano L. Caspase-8 goes cardiolipin: a new platform to provide mitochondria with microdomains of apoptotic signals? J Cell Biol 2008; 183: 579-581.

28. Sorice M, Matarrese P, Tinari A, Giammarioli AM, Garofalo T, Manganelli $V$ et al. Raft component GD3 associates with tubulin following CD95/Fas ligation. FASEB J 2009; 23: 3298-3308

29. Parone PA, Martinou JC. Mitochondrial fission and apoptosis: an ongoing trial. Biochim Biophys Acta 2006; 1763: 522-530

30. Martinou JC, Youle RJ. Which came first, the cytochrome $c$ release or the mitochondrial fission? Cell Death Differ 2006; 13: 1291-1295.

31. Suen DF, Norris KL, Youle RJ. Mitochondrial dynamics and apoptosis. Genes Dev 2009; 22: $1577-1590$.

32. Cipolat S, Rudka T, Hartmann D, Costa V, Serneels L, Craessaerts K et al. Mitochondrial rhomboid PARL regulates cytochrome $c$ release during apoptosis via OPA1-dependent cristae remodeling. Cell 2006; 126: 163-175.

33. Frezza C, Cipolat S, Martins de Brito O, Micaroni M, Beznoussenko GV, Rudka T et al. OPA1 controls apoptotic cristae remodeling independently from mitochondrial fusion. Cell 2006; 126: 177-189. 
34. de Brito OM, Scorrano L. Mitofusin 2: a mitochondria-shaping protein with signaling roles beyond fusion. Antioxid Redox Signal 2008; 10: 621-633.

35. Cereghetti GM, Scorrano L. The many shapes of mitochondrial death. Oncogene 2006; 25 : 4717-4724.

36. Satoh M, Hamamoto T, Seo N, Kagawa Y, Endo H. Differential sublocalization of the dynamin-related protein OPA1 isoforms in mitochondria. Biochem Biophys Res Commun 2003; 300: 482-493.

37. Marasas WF, Riley RT, Hendricks KA, Stevens VL, Sadler TW, Gelineau-van Waes J et al. Fumonisins disrupt sphingolipid metabolism, folate transport, and neural tube development in embryo culture and in vivo: a potential risk factor for human neural tube defects among populations consuming fumonisin-contaminated maize. J Nutr 2004; 134: 711-716.

38. Inokuchi J, Radin NS. Preparation of the active isomer of 1-phenyl-2-decanoylamino-3morpholino-1-propanol, inhibitor of murine glucocerebroside synthetase. J Lipid Res 1987; 28: $565-571$.
39. Malorni W, Garofalo T, Tinari A, Manganelli V, Misasi R, Sorice M. Analyzing lipid raft dynamics during cell apoptosis. Methods Enzymol 2008; 442: 125-140.

40. Rodgers W, Rose JK. Exclusion of CD45 inhibits activity of p56lck associated with glycolipid-enriched membrane domains. J Cell Biol 1996; 135: 1515-1523.

41. Skibbens JE, Roth MG, Matlin KS. Differential extractability of inuenza virus hemagglutinin during intracellular transport in polarized epithelial cells and nonpolar broblasts. J Cell Biol 1989; 108: 821-832.

42. Svennerholm L, Fredman PA. A procedure for the quantitative isolation of brain gangliosides. Biochim Biophys Acta 1980; 617: 97-109.

43. Williams MA, McCluer $\mathrm{RH}$. The use of Sep-Pak C18 cartridges during the isolation of gangliosides. J Neurochem 1980; 35: 266-269.

44. Zamzami N, Maisse C, Metivier D, Kroemer G. Measurement of membrane permeability and permeability transition of mitochondria. Methods Cell Biol 2001; 65: 147-158.

Supplementary Information accompanies the paper on Cell Death and Differentiation website (http://www.nature.com/cdd) 